\title{
Passivo Ambiental: Estudo de Caso da Petróleo Brasileiro S.A - Petrobrás. A Repercussão Ambiental nas Demonstrações Contábeis, em Conseqüência dos Acidentes Ocorridos
}

\author{
Ana Lúcia Bertoli \\ Maisa de Souza Ribeiro
}

\begin{abstract}
ResUmo
As demonstrações contábeis são muito importantes para que os acionistas, investidores, fornecedores, financiadores e interessados saibam a situação patrimonial e o resultado da empresa com a qual se relaciona, bem como sua forma de atuação em relação ao meio ambiente, seu comprometimento com a natureza e com a legislação vigente. A ausência dessas informações ou a inexistência de sua segregação pode velar o impacto decorrente de gastos ambientais proativos ou reativos. Os investimentos para a preservação e proteção do meio ecológico têm valores expressivos; no entanto os gastos necessários para fazer face às consequiências da ausência de medidas preventivas ou falhas operacionais podem atingir volumes muito mais comprometedores em face do patrimônio e do resultado das companhias. As demonstrações contábeis da companhia Petrobrás foram utilizadas como estudo de caso, tendo em vista a obrigatoriedade de publicação e os diversos acidentes ocorridos em 2000 e 2001. O trabalho teve como objetivo apurar o efeito dos impactos ambientais sobre a situação econômico-financeira da empresa. Constatou-se que os efeitos foram significativos e certamente poderiam ser comprometedores, se ocorressem em empresas com estruturas diferenciadas em relação ao porte, à participação do governo no capital e à concentração das atividades.
\end{abstract}

Palavras-chave: contabilidade ambiental; passivo ambiental; responsabilidade social; situação patrimonial.

\begin{abstract}
Financial statements are very important for stockholders, investors, suppliers, funders and interested parties to know about the equity situation and result of a company, as well as how it relates to the environment, its commitment to nature and to current legislation. The absence of this information or the inexistence of its segregation can hide the impact of proactive or reactive environmental spending. Although investments in ecological preservation and protection can reach significant amounts, the spending needed to face the consequences of a lack of preventive measures or operational breakdowns can amount to much more compromising levels in relation to company equity and results. The financial statements of Petrobrás were used as a case study, in view of obligatory disclosure and the different accidents that occurred in 2000 and 2001. This study aimed to determine the effect of environmental impacts on the company's economic and financial situation. Significant effects were observed, which could certainly be compromising if they occurred in companies with differentiated structures in terms of size, the government's capital interests and activity concentration.
\end{abstract}

Key words: environmental accounting; environmental liabilities; social responsibility; equity situation. 


\section{INTRODUÇÃO}

A idéia de estudar os impactos ambientais no patrimônio da empresa Petróleo Brasileiro S. A. - Petrobrás surgiu devido a inúmeros acidentes ocorridos com ela, os quais ocasionaram danos com conseqüências gravíssimas e, muitas vezes, irreparáveis ao meio ambiente, à população e à própria empresa.

Algumas empresas, em suas atividades, interagem diretamente com a natureza, alterando sua forma original, seja por meio do uso de recursos provenientes dela, da liberação de poluentes ou de outras formas que possam alterar suas condições.

O conceito de proteção à natureza para alguns já se vem firmando como dever de todos, mas ainda é necessária uma evolução nesse sentido. Dentro do conceito de responsabilidade social das empresas, está embutida a prevenção de danos à natureza; desta forma, muitas empresas já se vêm empenhando em fazê-lo.

Observa-se a adequação da inclusão das informações ambientais nos relatórios contábeis (ativos e passivos ambientais), assim como sua disseminação, para que os vários grupos de usuários avaliem a preocupação da empresa com seu papel social, seu posicionamento em relação ao ambiente, formulando e implementando idéias, atitudes e condutas que promovam melhorias no curto e no longo prazo, as quais se refletirão na imagem da empresa e em sua situação patrimonial.

Por meio da Contabilidade, que possui como objetivo principal permitir a cada grupo de usuários a avaliação da situação econômica e financeira da entidade e da sua vertente ambiental, que possibilita a demonstração da atuação ambiental da empresa, podem-se entender, de forma mais clara, os impactos dos acidentes em que a Petrobrás esteve envolvida, sua preocupação com esta área e como ela vem agindo para preveni-los ou mesmo diminuir seus efeitos, no caso da impossibilidade de impedí-los.

Como, em muitos casos, as conseqüências desses acidentes são de difícil mensuração, por atingirem áreas extensas e perdurarem por muitos anos, alguns efeitos podem ser avaliados e relacionados ao desempenho econômico-financeiro da empresa, mesmo nos casos que existam pendências judiciais, que implicam morosidade, mas que apresentam grande probabilidade de desembolso financeiro por parte da empresa.

Nesse sentido, este trabalho procura demonstrar a viabilidade de uma postura empresarial mais clara em relação à natureza, demonstrando que, ao provisionar 
seus passivos ambientais considerando princípios contábeis como o da competência e da prudência, é possível obterem-se resultados mais fiéis à realidade, em suas demonstrações contábeis.

\section{Hipóteses Trabalhadas}

Para a obtenção das inferências, foram simuladas duas hipóteses.

A primeira consiste em que a falta de segregação do fator ambiental pode velar as ações empresariais nesse sentido. Fez-se uma simulação, destacando os fatores ambientais que estão contidos nas demonstrações contábeis - Balanço Patrimonial e Demonstração de Resultado -, facilitando a observação dos procedimentos que se referem a esta área e das suas implicações. A falta de segregação da variável ambiental pode velar a real preocupação da empresa e o que vem sendo implementado nessa área, dificultando a visualização de seus esforços, assim como as consequiências ambientais decorrentes de acidentes envolvendo suas atividades operacionais.

A segunda consiste em que a falta de provisionamento de passivos ambientais pode alterar o resultado do exercício no qual ocorrem. Simulou-se, além das alterações realizadas para a obtenção da primeira inferência, alguns impactos ambientais de acidentes em que a empresa esteve envolvida e que não haviam sido provisionados em suas demonstrações contábeis, como ações judiciais que estão sob contestação e que implicarão o pagamento de multas e/ou indenizações de valores, os quais podem, por não serem considerados e demonstrados, camuflar a situação, afetando a atuação futura da empresa.

Obedecendo ao Princípio Contábil da Competência, deve-se confrontar despesa e receita no mesmo exercício em que ocorrem. Assim, uma vez ocorrido o dano ambiental, a obrigação de se arcar com os efeitos causados por ele é uma realidade e necessária se faz uma provisão para seu pagamento, mesmo que o valor respectivo e a responsabilidade pelo dano ainda estejam sob contestação, pois a probabilidade do efetivo pagamento é maior do que a sua negativa, o que é exemplificado por casos similares anteriormente ocorridos; sabendo-se, ainda, que por fazerem parte do respectivo exercício, faz-se necessária sua apropriação e demonstração no mesmo, para que não venham a comprometer os demais exercícios, distorcendo não só o resultado atual, mas também os futuros.

\section{Contabilidade Ambiental}

Durante muitos anos, os empresários resistiram em investir na área ambiental, 
por pensar que tais investimentos reduziriam o resultado. Atualmente, esta visão mudou e percebe-se que a ausência de recursos nessa área pode comprometer até mesmo a continuidade da empresa.

Assim, tornou-se muito importante obter informações objetivas e claras sobre a postura ambiental adotada pelas companhias. Quando as empresas possuem passivos ambientais e estes não se encontram identificados, isto pode comprometer sua manutenção e provocar grande prejuízo aos demais envolvidos, pois estes não terão subsídios para uma correta e real avaliação da situação da empresa e, desta forma, não poderão julgar a viabilidade de fazerem investimentos nela.

Verifica-se que, durante o período em que houver o investimento na área ambiental, o lucro poderá ficar reduzido; mas, em períodos futuros, tais gastos possivelmente evitarão outros ainda maiores e de difícil mensuração, como multas e indenizações a terceiros, sem contar o benefício de se conseguir a proteção e preservação do meio ambiente ao invés da sua recuperação, que jamais será conseguida integralmente após um dano ambiental.

Segundo Ribeiro (1992, p. 56),

a contabilidade, enquanto instrumento de comunicação entre empresas e sociedade, poderá estar inserida na causa ambiental. A avaliação patrimonial, considerando os riscos e benefícios ambientais inerentes às peculiaridades de cada atividade econômica, bem como sua localização, poderá conscientizar os diversos segmentos de usuários das demonstrações contábeis sobre a conduta administrativa e operacional da empresa, no que tange ao empenho da empresa sobre a questão.

Definida como o estudo do patrimônio ambiental (bens, direitos e obrigações ambientais) das entidades, a Contabilidade Ambiental apresenta como objetivo fornecer aos seus usuários, internos e externos, informações sobre os eventos ambientais que causam modificações na situação patrimonial, bem como realizar sua identificação, mensuração e evidenciação (Santos, 2001, p. 91).

\section{Passivos Ambientais}

Os passivos ambientais se vêm acumulando no Brasil ao longo de cinco séculos de atividades humanas realizadas com descaso diante do meio ambiente e da sua capacidade de resiliência para suportar tais agressões, provocando manifestações das mais variadas formas.

O passivo ambiental representa o sacrifício de benefícios econômicos que serão realizados para a preservação, recuperação e proteção do meio ambiente, de 
forma a permitir a compatibilidade entre o desenvolvimento econômico e o meio ecológico ou em decorrência de conduta inadequada em relação às questões ambientais (Ribeiro, 2000). Diz respeito não só às sanções por degradação ambiental, mas também às medidas empresariais para a prevenção de danos ambientais, que têm reflexos econômico-financeiros, comprometendo tanto o presente quanto o futuro da empresa, exemplificado nas situações em que a empresa tem de assumir a responsabilidade pelas consequiências de suas atividades operacionais, como o depósito de resíduos no meio ambiente.

Para a identificação do passivo ambiental das empresas, entre as formas possíveis, segundo Ribeiro e Lisboa (1999), estaria o uso das informações contidas tanto no EIA quanto no RIMA:

. EIA - Estudo de Impacto Ambiental: que pode ser exigido no licenciamento de projetos de empreendimentos e atividades considerados efetivos ou potencialmente causadores de significativa degradação do meio ambiente. $\mathrm{O}$ artigo $2^{\circ}$. da Resolução 01/86 e o anexo 01 da Resolução 237/97, ambas do Conselho Nacional do Meio Ambiente (Conama), apresentam uma listagem exemplificativa dos empreendimentos e atividades sujeitos ao licenciamento, sendo que o parágrafo $2^{\circ}$. do artigo 18 da referida Resolução esclarece que os órgãos ambientais competentes avaliarão a necessidade do EIA em cada caso, considerando as especificidades, os riscos ambientais, o porte e outras características do empreendimento ou atividade.

- RIMA - Relatório de Impacto ao Meio Ambiente: deve refletir as conclusões do EIA, contendo, entre outros aspectos, os objetivos e justificativas do projeto; as alternativas tecnológicas e locacionais; uma síntese dos resultados dos estudos de diagnósticos ambientais; a descrição dos prováveis impactos ambientais da implantação e operação da atividade; a caracterização da qualidade ambiental futura; a descrição do efeito esperado das medidas mitigadoras previstas em relação aos impactos; o programa de acompanhamento e monitoramento dos impactos; e, por fim, recomendações quanto à alternativa mais favorável. Tudo isso de forma objetiva, compreensível, com linguagem acessível ao público em geral.

Também como auxílio à obtenção de informações sobre o passivo ambiental na contabilidade das empresas, pode-se dispor da due diligence inspection, que

se refere a um trabalho direcionado para a identificação de todos os aspectos econômicos, financeiros e físicos que estejam afetando, ou poderão vir a afetar a situação patrimonial da companhia. Nesse contexto, certamente as variáveis ambientais também serão alvo de atenção. Tal trabalho é executado por uma equipe de profissionais externos e especializados (Ribeiro \& Lisboa, 2000). 
Como observa Ribeiro (1999, p. 5):

Através das informações ambientais incluídas no Balanço Patrimonial das empresas, é possível aos interessados na sua continuidade (administradores, gerentes, acionistas, potenciais investidores, fornecedores, instituições financeiras, etc.) terem elementos para análise e inferências sobre as providências tomadas pela empresa para evitar que seus procedimentos operacionais produzam agressões ao meio ambiente, bem como sobre a relação dos efeitos econômico-financeiros desses impactos com a situação patrimonial.

Entre outras, algumas das penalidades legais, que podem comprometer a continuidade das atividades, em especial nos casos das empresas potencialmente poluidoras e que não adotam medidas preventivas para minimizar os danos por elas causados, assim como não correspondem às normas estabelecidas em lei, são: multas por infrações; obrigatoriedade de recuperação ou restauração de áreas degradadas; interdição governamental das atividades, em casos de infrações abusivas ou reincidentes.

\section{Quando Contabilizar?}

Segundo Ribeiro e Lisboa (1999), o passivo representa as obrigações das empresas para com terceiros e, de acordo com as premissas contábeis, tais obrigações devem ser reconhecidas a partir do momento em que são verificadas, mesmo que ainda não haja uma cobrança formal ou legal. As obrigações, cujos fatos geradores já tenham ocorrido, também deverão ser reconhecidas como passivo ambiental, desde que configurem responsabilidade da empresa nessa área, mesmo que para isso sejam usados cálculos estimativos para se obterem os montantes correspondentes. Quando houver impossibilidade de mensuração dos passivos ambientais, deverão ser inseridas notas explicativas.

\section{Contingencias}

Segundo Jucovsky (2002), as contingências representam "os riscos da empresa quanto a situações futuras". As contingências acarretam expectativas de despesas futuras, ou receitas, a exemplo da procedência ou improcedência de recurso administrativo ou ação judicial em que a empresa impugnar a responsabilidade quanto aos resíduos de sua atividade operacional e que causaram impacto no meio ambiente; ou gastos com multas, restauração ambiental, indenizações a terceiros, atuações preventivas e outros.

Ainda deve ser levada em conta a possibilidade de danos futuros resultantes de 
ações ou omissões passadas da empresa que, por sua vez, precisarão ser avaliados e que poderão implicar novas despesas (Jucovsky, 2002).

\section{Legislação Ambiental}

Inicialmente, a tutela ambiental era tratada de maneira esparsa no ordenamento jurídico brasileiro, sendo o Código Civil o primeiro a ditar várias regras sobre a proteção ambiental. Em 1937, o Decreto Lei 25 foi instituído para tratar da proteção do patrimônio histórico e artístico nacional; em 1965 a Lei 5.197 veio legislar sobre a proteção de florestas nativas; em 1967 foi a vez da fauna silvestre por meio da Lei 5.197; as atividades nucleares foram regulamentadas pela Lei 6.453, em 1977; o parcelamento urbano recebeu tratamento legal por meio da Lei 6.766, em 1979; a Lei 6.803/80 veio legislar o zoneamento industrial das áreas críticas de poluição (Machado, 1999). Por fim, em 1981, a Lei 6.938, introduziu a Política Nacional do Meio Ambiente, com uma visão holística da proteção ao meio ambiente como sistema ecológico integrado e autônomo, ou seja, como bem jurídico (Jucovsky, 2002).

Com a referida lei, ocorreu o início da tutela ambiental no Brasil, sendo estabelecidos os princípios, objetivos e instrumentos da Política Nacional de Meio Ambiente. Entre os referidos instrumentos está arrolada a avaliação de impactos ambientais, que foi regulamentada pela Resolução n ${ }^{\text {. }}$ 01/86 do Conama e ratificada pela Resolução 237/97 do mesmo órgão.

A Constituição Federal de 1988 foi a primeira Carta brasileira a cuidar do assunto de modo específico e explícito, e é tida como uma das mais avançadas em comparação com os textos de outros países e as leis consideradas mais relevantes para a proteção do meio ambiente no Brasil, segundo Jucovsky (2002), são:

- Decreto-lei 1.413/75, sobre o controle da poluição do meio ambiente provocada por atividades industriais, em seu artigo $1^{\circ}$ estabelece que as indústrias devem adotar condições para "prevenir ou corrigir os inconvenientes e prejuízos da poluição e da contaminação do meio ambiente".

. Lei 6.938/81 - Lei da Política Nacional do Meio Ambiente.

. Lei 7.347/85 - Lei da Ação Civil Pública, mecanismo processual especial para a tutela ambiental e de outros interesses coletivos e difusos.

. Constituição Federal de 1.988 - Parâmetro para as Constituições dos Estadosmembros e as Leis Orgânicas Municipais. 
- A Lei 8.078/90 - O Código do Consumidor, que fez com que a Lei da Ação Civil Pública passasse a ser utilizada para a proteção dos interesses transindividuais, dos consumidores e do meio ambiente.

. Lei 9.605/98 - A Lei dos Crimes Ambientais, que trata dos crimes e infrações administrativas ambientais.

- Decreto $\mathrm{n}^{\circ} 3.179$, de 21 de setembro de 1999, que trata das sanções penais e administrativas quanto às condutas e atividades lesivas ao ambiente.

$\mathrm{O}$ art. 225, $\S 3^{\circ}$, da Constituição Federal Brasileira estabelece três modalidades de responsabilidade por dano ambiental, que são sancionadas de forma independente e podem ser cumulativas: civil, administrativa e penal (Jucovsky, 2002).

O sujeito passivo da responsabilidade civil pela reparação do dano ambiental é o poluidor, "pessoa física ou jurídica, de direito público ou privado, responsável de forma direta ou indireta, pela atividade (ação ou omissão) que tenha causado degradação no meio ambiente" (art. $3^{\circ}$, IV e $14, \S^{\circ}$, da Lei 6.938/81); fundamentase no princípio do poluidor-pagador e na teoria da responsabilidade civil objetiva (Jucovsky, 2002).

Ainda, como citam Ribeiro e Lisboa (1999, p. 77):

A responsabilidade que poderá ser imputada aos novos proprietários pelos efeitos nocivos ao meio ambiente provocados pelo processo operacional da companhia ou pela forma como os resíduos poluentes foram tratados, independentemente da pessoa que figure ou que figurou como proprietário na ocasião em que o fato gerador da penalidade ocorreu, em caso de descoberta posterior ao momento da negociação.

\section{Estudo do Caso}

\section{Companhia Petróleo Brasileiro S.A. - Petrobrás}

A Petrobrás é uma sociedade anônima de capital aberto que atua de forma integrada e especializada nos seguintes segmentos relacionados à indústria de óleo, gás e energia: exploração e produção; refino, comercialização, transporte e petroquímica; distribuição de derivados; gás natural e energia (Petrobrás, 2001).

Os fatos a seguir transcritos foram obtidos nos relatórios anuais, publicados pela companhia, referentes aos períodos de 1999 a 2001. 


\section{Atuação Ambiental}

A Petrobrás desenvolveu o Programa de Excelência em Gestão Ambiental e Segurança Operacional (Pégaso), o qual teria recebido, de 2000 a 2003, investimentos de $\mathrm{R} \$ 5,15$ bilhões (Petrobrás, 2000, p. 10-27; 2001, p. 11).

O Pégaso atua nas áreas de: prevenção, contingência, resíduos, efluentes, emissões, gestão, relacionamento com a sociedade, segurança do trabalho (Petrobrás, 2001, p. 11), agindo nas áreas: preventiva, gerencial, emergencial e de prevenção de acidentes. Nota-se a busca pelo relacionamento com a sociedade por meio dos convênios firmados com ONGs, Universidades, Governo e Comunidades (Petrobrás, 2000, p. 10).

No que se refere à Segurança, ao Meio Ambiente e à Saúde, a Petrobrás está implementando um programa que visa a adequá-la aos padrões internacionais até 2005 (Petrobrás, 2000).

\section{Acontecimentos no Ano de 2000}

\section{Acidentes Ocorridos}

A) Janeiro - Baía de Guanabara (Rio de Janeiro): 1.292 mil litros de óleo, equivalentes a 8.000 barris.

Em 18 de janeiro de 2000, ocorreu um vazamento de óleo combustível resultante da ruptura de um dos nove oleodutos que ligam a Refinaria Duque de Caxias (Reduc) ao terminal da Petrobrás na Ilha D’Água. O vazamento atingiu principalmente a área do fundo da baía de Guanabara, causando danos ao meio ambiente e às comunidades da região (Petrobrás, 2000, p. 27).

Gastos decorrentes: aproximadamente R \$103,7 milhões com trabalhos de contenção do óleo, recuperação das áreas afetadas, compensações/indenizações, incluindo uma multa no valor de $\mathrm{R} \$ 35$ milhões aplicada com base na legislação brasileira e a contribuição de $\mathrm{R} \$ 15$ milhões para um fundo de proteção da Baía de Guanabara mantido pelo Governo Federal. E, ainda, os gastos decorrentes de ações criminais movidas pela Promotoria do Estado do Rio de Janeiro e Promotoria Pública Federal contra a Petrobrás, seu presidente e 9 funcionários (Petrobrás, 2000, p. 27 e 30).

B) Julho - Araucária (Paraná): 4 milhões de litros de óleo ou 25.000 barris.

Em 16 de julho de 2000, ocorreu vazamento de óleo em uma unidade de transferência e estocagem da Refinaria Getúlio Vargas - Repar, no município de Araucária, a 24 km de Curitiba, no Paraná, que atingiram os rios Barigüi e 
Iguaçu e depois espalharam-se por cerca de $10 \mathrm{~km}$ no rio Iguaçu (Petrobrás, 2000, p. 30).

Gastos decorrentes: aproximadamente R \$ 74 milhões, incluindo R \$ 40 milhões em multas aplicadas pelo Instituto Ambiental do Paraná para a limpeza dos rios atingidos. Adicionalmente, uma multa de R 168 milhões aplicada pelo Instituto do Meio Ambiente e dos Recursos Naturais Renováveis (Ibama), em $1^{\circ}$ de agosto de 2000 (Petrobrás, 2000, p. 27). As Promotorias da República e do Estado do Paraná moveram ação civil contra a Companhia, reclamando R\$2.707.907 mil por perdas e danos (Petrobrás, 2001, p. 30).

Neste caso, o valor da ação civil pública, protocolada conjuntamente pelo Ministério Público Federal e o Ministério Público do Estado do Paraná, devido ao vazamento de quatro milhões de litros de óleo no Rio Iguaçu, corresponde a um quarto do lucro da estatal em 1999, ou então cerca de 1/12 avos de seu faturamento no mesmo período. A tese jurídica, que segue a mais moderna doutrina jurídica e ainda sem precedentes na história brasileira, leva em conta a capacidade financeira da empresa para o cálculo da indenização. No total, a ação contém 40 pedidos, entre eles, indenização também por danos morais, com valor a ser estipulado pelo juiz e a imposição à Petrobrás de apresentar ao Instituto Ambiental do Paraná e ao Ibama novos Estudos de Impactos Ambientais, para todas as atividades da refinaria (Gazeta do Povo, 2001).

Os promotores em estudo defendem que a fixação de indenizações por danos ambientais deve ter como base: "as proporções do acidente; -suas consequiências ambientais; eventuais reincidências; a capacidade econômica do agente poluidor" (Gazeta do Povo, 2001). Os promotores observam que é preciso que o infrator pague quantia correspondente a uma relevante parte de seu lucro, de maneira que a empresa perca aquilo que lucrou com sua operação e se advirta de que não vale a pena, economicamente, operar sem instrumentos de proteção instrumental, argumentando ainda que é indispensável que o infrator sofra uma perda econômica considerável para que a função pedagógica do direito ambiental se realize (Gazeta do Povo, 2001).

C) Novembro - São Sebastião (São Paulo): 86 mil litros de óleo ou 700 barris.

No dia 04 de novembro de 2000, o navio Vergina II, de bandeira cipriota, afretado pela Petrobrás, colidiu com o pier Sul do Terminal Almirante Barroso (DTCS) de propriedade da Companhia em São Sebastião no canal de São Sebastião. Em decorrência dos ventos e das correntezas, o óleo derramado atingiu posteriormente as praias de São Sebastião e Ilhabela (Petrobrás, 2000, p. 27).

Gastos decorrentes: aproximadamente $\mathrm{R} \$ 50$ milhões de multa aplicada pela Agência Ambiental de São Paulo (Cetesb) e aproximadamente R \$ 7 milhões pela Prefeitura de São Sebastião. (Petrobrás, 2000). 


\section{Acontecimentos no Ano de 2001}

\section{Acidentes Ocorridos}

A) Fevereiro - Morretes (Paraná): 50 mil litros de óleo ou 340 barris

Em 16 de fevereiro houve o rompimento de um oleoduto em Morretes - Paraná (Petrobrás, 2001, p. 30).

Gastos decorrentes: 13 multas por danos ambientais que totalizaram de $\mathrm{R} \$$ 174.030 mil aplicadas pelo Instituto Ambiental do Paraná (Petrobrás, 2001, p. 30).

O referido acidente deu origem ao maior valor já pleiteado por dano ambiental apresentado à Justiça Brasileira e teve a iniciativa do Ministério Público Federal conjuntamente com o Ministério Público do Estado do Paraná. A ação pede a condenação da Companhia em até $\mathbf{R} \$ \mathbf{3 , 7}$ bilhões, por danos ambientais. $\mathrm{O}$ referido montante estaria baseado no faturamento de $\mathbf{2 0 0 0}$ da Petrobrás e corresponderia a um doze avos da receita líquida da companhia naquele ano, segundo explicam as promotoras e o procurador envolvidos na ação (Folha, 2002).

O procurador da República João Gualberto Garcez Ramos justificou o valor defendido na reincidência de acidentes na Petrobrás (Folha, 2002). O art. 10 do Decreto n. 3179/99 permite "a agravação da pena em até três vezes, no caso de reincidência específica" (Decreto n. 3179/99). Ele relacionou 16 desastres envolvendo a estatal, entre março de 97 a fevereiro de 2001. O Relatório de Atividades da Companhia de 2001 divulgou que a ação pública referente ao acidente reclamava o montante de $\mathbf{R} \mathbf{\$} \mathbf{2 . 7 0 7 . 9 0 7} \mathbf{~ m i l}$, valor este assumido neste estudo, atendendo ao Princípio Contábil da Prudência.

B) Março - Campo do Roncador (Bacia de Campos - Rio de Janeiro): 1.200 metros cúbicos de óleo diesel e 300 metros cúbicos de petróleo, equivalente a 78.400 barris e 11 mortes.

O acidente ocorrido em 15 de março de 2001 culminou com o afundamento da plataforma semi-submersível de produção P-36, que operava no Campo de Roncador (RJ). Este acidente foi citado pelos presidentes da Petrobrás e do Conselho da Administração, como um dos mais sérios acidentes da história da Petrobrás (Petrobrás, 2001).

Gastos decorrentes: multa de $\mathrm{R} \$ 7$ milhões aplicada pelo Ibama (Petrobrás, 2001, p. 30).

C) Outubro - Paranaguá (Paraná): derramamento de 392 mil litros de nafta. 
Em 18 de outubro colisão do navio Norma da Transpetro com uma pedra, à saída do porto de Paranaguá.

Gastos decorrentes: multa de $\mathrm{R} \$ 50$ mil aplicada pela Capitania dos Portos e de R 5 milhões pelo Ibama (Petrobrás, 2001, p. 30).

\section{ANÁlise dos Impactos}

\section{Aplicação da Hipótese 1: Segregação das Informações Ambientais}

A falta de segregação do fator ambiental pode velar as ações empresariais neste sentido.

Realizou-se uma simulação, destacando os fatores ambientais que estão contidos nas demonstrações contábeis - Balanço Patrimonial e Demonstração de Resultados - apresentadas pela Petrobrás, referentes aos exercícios de 1999, 2000 e 2001, na forma de Controladora, em milhares de reais, facilitando a observação dos procedimentos que se referem a esta área e das suas implicações.

\begin{tabular}{|l|r|r|r|}
\hline BALANÇO PATRIMONIAL & 1999 & 2000 & 2001 \\
\hline ATIVO & & & \\
\hline Total do Circulante & 12.341 .975 & 21.356 .808 & 27.707 .412 \\
\hline Total do Realizável a Longo Prazo & 17.648 .958 & 16.918 .902 & 16.672 .103 \\
\hline PERMANENTE & & & \\
\hline Investimentos & 8.647 .282 & 9.699 .140 & \\
\hline Imobilizado & 15.268 .398 & 16.507 .881 & 18.494 .179 \\
\hline Programa de Excelência Ambiental & & $\mathbf{5 5 0 . 0 0 0}$ & \\
\hline Projetos de desempenho ambiental & $\mathbf{1 8 9 . 0 0 0}$ & & $\mathbf{1 . 4 0 0 . 0 0 0}$ \\
\hline Diferido & 424.644 & 535.756 & \\
\hline Total do Permanente & 24.340 .324 & 26.742 .777 & 27.503 .303 \\
\hline \hline TOTAL DO ATIVO & 54.331 .257 & 65.018 .487 & 71.882 .818 \\
\hline \hline
\end{tabular}

Os investimentos no Programa de Excelência Ambiental, em destaque, em 2000 e 2001, são os referentes ao Programa de Excelência em Gestão Ambiental e Segurança Operacional (Pégaso), constantes das demonstrações contábeis dos referidos períodos. Projetos de desempenho ambiental comportam os gastos diretos incorridos no desenvolvimento de projetos de controle ambiental, conforme as informações contábeis de 2000. 
Em princípio, tais valores já estariam registrados na contabilidade da Companhia, sendo a proposta deste trabalho destacá-los dos demais elementos patrimoniais, para dar transparência aos esforços realizados para proteger o meio ambiente.

No Passivo deveria haver menção explícita dos valores ainda devidos a terceiros em função do desenvolvimento do referido programa, além do montante de obrigações necessárias para sua manutenção em funcionamento, como a mãode-obra especializada, por exemplo. No Patrimônio Líquido não haveria nenhum destaque a ser feito, nesta situação.

O resultado teria tido os seguintes reflexos:

\begin{tabular}{|c|c|c|c|}
\hline DEMONSTRAÇÃO DO RESULTADO & 1999 & 2000 & 2001 \\
\hline Receita Operacional Bruta (Prod/Serv) & 36.654 .037 & 57.196 .072 & 68.342 .118 \\
\hline Encargos de Vendas & $(9.772 .616)$ & $(12.568 .415)$ & $(19.249 .211)$ \\
\hline Receita Operacional Líquida & 26.881 .421 & 44.627 .657 & 49.092 .907 \\
\hline Custo dos Produtos Vendidos e Serv. Prestados & $(17.545 .438)$ & $(25.686 .488)$ & $(29.613 .058)$ \\
\hline Lucro Bruto & 9.335 .983 & 18.941 .169 & 19.479 .849 \\
\hline Desp. Operacionais (de a até g) & $(8.220 .675)$ & $(5.708 .999)$ & $(7.673 .140)$ \\
\hline a) Vendas & $(691.311)$ & $(900.224)$ & $(1.666 .047)$ \\
\hline b) Financeiras & $(5.323 .748)$ & $(1.030 .345)$ & $(511.982)$ \\
\hline c) Gerais e Administrativas & $(677.096)$ & $(865.372)$ & $(1.236 .894)$ \\
\hline d) Tributárias & $(222.722)$ & $(343.534)$ & $(531.885)$ \\
\hline e) Custos c/ Pesquisas e Desenvolv. Tecnológico & $(217.899)$ & $(83.689)$ & $(308.888)$ \\
\hline f) Custos p/ Exploração de Petróleo e Gás & $(439.162)$ & $(1.003 .988)$ & $(876.804)$ \\
\hline g) Outras Despesas Operacionais Líquidas & $(648.737)$ & $(1.481 .847)$ & $(2.540 .640)$ \\
\hline h) Participações em Subsidiárias e Coligadas & 938.863 & 1.252 .524 & 2.530 .681 \\
\hline Lucro Operacional & 2.054 .171 & 14.484 .694 & 14.337 .390 \\
\hline Resultados ambientais & & (177.700) & \\
\hline Contençao, recuperação, compensações/indenizações & & $(87.700)$ & \\
\hline Multas ambientais & & $(75.000)$ & \\
\hline Contribuição para fundo de proteção & & $(15.000)$ & \\
\hline Resultados não Operacionais & 57.832 & $(23.053)$ & $(259.286)$ \\
\hline Receitas não operacionais & & & 26.466 \\
\hline Perdas por Acidentes Ambientais & & & $(285.752)$ \\
\hline LUCRO antes do IR, CSLL e Participações & 2.112 .003 & 14.283 .941 & 14.078.104 \\
\hline IR, CSLL, Particip. de Empregados e Minoritária & $(340.599)$ & $(4.124 .271)$ & $(3.784 .214)$ \\
\hline Lucro Líquido do Exercício & 1.771 .404 & 10.159 .670 & 10.293 .890 \\
\hline
\end{tabular}


$\mathrm{O}$ valor das multas ambientais tem a seguinte composição: $\mathrm{R} \$ 35.000 \mathrm{mil}$ referente ao acidente ocorrido na Baia da Guanabara, no Rio de Janeiro, em janeiro de 2000; e R \$ 40.000 mil referente ao acidente ocorrido em Araucária, no Paraná, em julho do mesmo ano.

As informações sobre os custos de contenção, recuperação, compensações, indenizações, multas ambientais e contribuição para o fundo de proteção, em destaque no demonstrativo retro, constavam do relatório anual de 2000. Provavelmente, estavam contabilizados, mas não foram destacados no corpo das demonstrações contábeis propriamente. Tal procedimento permite a análise econômica e financeira dos empreendimentos realizados para tratar os impactos ecológicos ocorridos no período.

A rubrica Perdas por Acidentes congrega os valores referentes à perda líquida por submersão da Plataforma P-36, no montante de R $\$ 153.015$, em março de 2001, e impossibilidade de recuperação das linhas e oleodutos ligados à P-36, resultando em uma baixa desses ativos e uma despesa de $\mathrm{R} \$ 132.737$, em dezembro, totalizando $\mathrm{R} \$ 285.752$. Com o destaque de tais valores pode-se visualizar o efeito das penalidades sobre o resultado do período, bem como em relação aos investimentos que deixaram de ser feitos.

Nesta hipótese, optou-se por alocar os custos ambientais como componentes de Custos c/ Pesquisas e Desenvolvimento Tecnológico.

\section{Efeitos da Hipótese 1}

A falta de segregação da variável ambiental pode velar a real preocupação da empresa e o que vem sendo implementado nessa área, dificultando a visualização de seus esforços, assim como as conseqüências ambientais decorrentes de acidentes envolvendo suas atividades operacionais.

\section{Aplicaçăo da Hipótese 2: Multas e Indenizações Não Provisionadas}

A falta de provisionamento de passivos ambientais pela empresa pode alterar o resultado do exercício no qual ocorrem.

Neste caso, simularam-se as demonstrações contábeis com os impactos dos acidentes ambientais em que a empresa esteve envolvida, considerando as ações judiciais, as multas e/ou indenizações de diversos valores; estes, por não serem 
considerados e demonstrados, podem camuflar as demonstrações, afetando a situação da empresa no futuro.

Adaptação da hipótese 2 às Demonstrações Contábeis - Balanço Patrimonial e Demonstração de Resultados - apresentadas pela Petrobrás, referentes aos exercícios de 1999, 2000 e 2001, na forma de Controladora, em milhares de reais:

\begin{tabular}{|l|r|r|r|}
\hline $\begin{array}{l}\text { PASSIVO E PATRIMÔNIO } \\
\text { LÍQUIDO }\end{array}$ & 1999 & 2000 & 2001 \\
\hline Total do Passivo Circulante & 19.948 .109 & 23.066 .010 & 25.778 .390 \\
\hline Total do Exigível a Longo Prazo & 16.724 .785 & 19.626 .500 & 20.279 .936 \\
\hline Provisão Ambiental & & $\mathbf{2 . 9 3 2 . 9 0 7}$ & $\mathbf{3 . 8 8 6 . 0 8 0}$ \\
\hline Multas & & $\mathbf{2 2 5 . 0 0 0}$ & $\mathbf{1 8 6 . 0 8 0}$ \\
\hline Indenizações & & $\mathbf{2 . 7 0 7 . 9 0 7}$ & $\mathbf{3 . 7 0 0 . 0 0 0}$ \\
\hline Total do Patrimônio Líquido & 17.658 .363 & 22.325 .977 & 25.824 .492 \\
\hline \hline TOTAL DO PASSIVO & 54.331 .257 & 65.018 .487 & 71.882 .818 \\
\hline \hline
\end{tabular}

Os valores das multas e indenizações foram assim obtidos:

\begin{tabular}{|l|r|r|}
\hline Ano de 2000 & \multicolumn{1}{|c|}{ Multas } & Indenizações \\
\hline Janeiro/ Baía de Guanabara & Valor não fixado & 2.707 .907 \\
\hline Julho/ Araucária & 168.000 & \\
\hline Novembro/ São Sebastião & 57.000 & \\
\hline Total em 2000 & $\mathbf{2 2 5 . 0 0 0}$ & $\mathbf{2 . 7 0 7 . 9 0 7}$ \\
\hline
\end{tabular}

\begin{tabular}{|l|r|r|}
\hline Ano de 2001 & Multas & Indenizações \\
\hline Fevereiro/ Morretes & 174.030 & 3.700 .000 \\
\hline Março/ Campo do Roncador & 7.000 & \\
\hline Outubro/ Paranaguá & 5.050 & \\
\hline Total em 2001 & $\mathbf{1 8 6 . 0 8 0}$ & $\mathbf{3 . 7 0 0 . 0 0 0}$ \\
\hline
\end{tabular}




\begin{tabular}{|c|c|c|c|}
\hline DEMONSTRAÇÃO DO RESULTADO & 1999 & 2000 & 2001 \\
\hline Receita Operacional Bruta (Prod/Serv) & 36.654 .037 & 57.196 .072 & 68.342 .118 \\
\hline \multirow[t]{2}{*}{ Demais itens.............................. } & & …................... & \\
\hline & a.... & …................. & ...... \\
\hline Lucro Operacional & 2.054 .171 & 14.484 .694 & 14.337 .390 \\
\hline Resultados ambientais & & (3.110.607) & $(3.886 .080)$ \\
\hline $\begin{array}{l}\text { Contençao, recuperação, } \\
\text { compensações/indenizações }\end{array}$ & & $(87.700)$ & \\
\hline Multas ambientais & & (75.000) & \\
\hline Contribuição para fundo de proteção & & (15.000) & \\
\hline $\begin{array}{l}\text { Multas ambientais (despesa criada em } \\
\text { contrapartida ao Passivo ambiental) }\end{array}$ & & $(225.000)$ & $(186.080)$ \\
\hline $\begin{array}{l}\text { Indenizações (despesa criada em contrapartida } \\
\text { ao Passivo ambiental) }\end{array}$ & & $(2.707 .907)$ & $(3.700 .000)$ \\
\hline Resultados não Operacionais & 57.832 & $(23.053)$ & $(259.286)$ \\
\hline Receitas não operacionais & & & 26.466 \\
\hline Perdas por Acidentes Ambientais & & & $(285.752)$ \\
\hline LUCRO antes do IR, CSLL e Participações & 2.112 .003 & 11.351 .034 & 10.192 .024 \\
\hline IR, CSLL, Particip. de Empregados e Minoritária & $(340.599)$ & $(4.124 .271)$ & $(3.784 .214)$ \\
\hline Lucro Líquido do Exercício & 1.771 .404 & 7.226 .463 & 6.407 .810 \\
\hline
\end{tabular}

Nesta simulação do resultado acrescentou-se, aos dados segregados anteriormente, a contrapartida dos valores inseridos no Passivo como obrigações que deverão ser cumpridas no futuro, referentes às multas e indenizações a terceiros.

\section{Efeitos da Hipótese 2}

No Passivo Exigível a Longo Prazo ocorreu um aumento:

. no ano de 2000: 2.932 .907 (de 16.693.593 para 19.626.500) - 17,57\%

. no ano de 2001: 3.886 .080 (de 16.393.856 para 20.279.936) - 23,70\%

No Patrimônio Líquido ocorreu uma redução:

. no ano de 2000: 2.932.907 (de 25.258.884 para 22.325.977) - 11,61\%

. no ano de 2001: 3.886 .080 (de 29.710.572 para 25.824.492) - 13,08\% 
No Lucro Líquido do Exercício ocorreu uma redução:

. no ano de 2000 de 2.932.907 (10.159.370 para 7.226.463) - 28,87\%

. no ano de 2001 de 3.886 .080 (10.293.890 para 6.407 .810$)-37,75 \%$

Com isso, observa-se que os impactos ambientais mencionados influenciaram, significativamente, a situação patrimonial da Companhia e seus resultados. Provavelmente, se não fossem as características políticas e econômicas de uma empresa de capital misto e que praticamente exerce o monopólio, além da descentralização das atividades, e portanto, dos acidentes, os stakeholders dessa Companhia teriam motivos para se preocupar com o retorno dos recursos aplicados.

\section{Conclusão}

Apesar das inúmeras atividades que a Petrobrás alega realizar para evitar danos ecológicos, observou-se que foram muitos os acidente ocorridos no período analisado.

Para que seja possível visualizar a preocupação da empresa com a área ambiental é fundamental a segregação das informações contábeis referentes a esta área, como foi demonstrado na hipótese 1 deste trabalho.

Desta forma, consegue-se destacar quanto vem sendo investido no meio ambiente, como melhorias tecnológicas para diminuição da emissão de poluentes, prevenção de acidentes, e outras medidas, adotadas com a finalidade de diminuir a capacidade lesiva apresentada pela empresa.

O provisionamento das multas e indenizações referentes a acidentes envolvendo a empresa, mesmo em casos de contestações judiciais, é relevante. Conforme observado na hipótese 2, as Demonstrações Contábeis que não apresentam as devidas provisões, relatam informações distorcidas, com o montante dos passivos subavaliados e o patrimônio líquido e o resultado de cada período superavaliados.

As ações judiciais, mesmo quando apresentam recursos, possuem grande probabilidade de obterem êxito, provocando uma repercussão negativa nas Demonstrações Contábeis, devido aos altos valores pleiteados, na grande maioria dos casos, principalmente nos de reincidência do fato gerador. Além do comprometimento da imagem da companhia ante a população, aos investidores, aos fornecedores de créditos e dos demais usuários de suas informações, envolvidos direta ou indiretamente com a empresa. 
Outro ponto observado, neste estudo, e que pode ser detalhado em pesquisas futuras, refere-se à correlação entre o crescimento das atividades da Petrobrás e o aumento das incidências dos acidentes, mesmo com o crescimento dos investimentos realizados na área ambiental.

Esta suposição ganha força no sentido de que, mesmo com a preocupação da empresa em prevenir acidentes ou mesmo saná-los, estes continuam ocorrendo. Assim, talvez o esforço nesse sentido esteja aquém do desenvolvimento operacional da companhia, ficando as medidas ambientais em patamar inferior ao necessário para o acompanhamento do desenvolvimento da empresa.

Nota-se, então, a importância das medidas ambientais, seu aprimoramento e adequação às necessidades desenvolvidas pelas empresas, porque, mesmo nos casos em que não ocorre negligência por parte das companhias, como se verificou neste estudo, ainda assim ocorrem acidentes de grande porte.

Em Petrobrás (2000), divulga-se que as ações da Companhia estão entre as que mais se vêm valorizando; mas, assim como as demais informações analisadas neste trabalho, esta informação pode estar camuflada pela falta de inserção de dados ambientais relativos aos períodos em que ocorreram passivos ambientais, comprometendo a empresa em exercícios futuros, podendo-se pensar em valorização imaginária ou fictícia dessas ações e da própria companhia, com a não incidência dos efeitos dos passivos ambientais nas Demonstrações Contábeis.

O montante representado por esses passivos deve ser relatado no respectivo exercício em que ocorrem, atendendo ao princípio da competência, adequandose também ao da prudência, uma vez que esses passivos ambientais (nos casos de pendências judiciais), apresentam grande probabilidade de virem a representar uma despesa para a empresa.

Devem-se confrontar as receitas geradas e despesas incorridas em um mesmo período, ainda que não realizadas financeiramente, dentre elas as ambientais, que vêm apresentando valores cada vez mais elevados, como nos casos das indenizações pedidas (ano de 2000: indenização de 2.707.907 mil, e ano de 2001: indenização de 3.700 .000 mil).

Com o relato dos passivos ambientais referentes aos respectivos anos de ocorrência, podem-se minimizar as distorções nos resultados apresentados pela companhia, passando-se de uma valorização potencialmente irreal, para o que ocorre efetivamente, sem que haja o comprometimento de exercícios futuros, com despesas que ainda serão realizadas, mas que já são do conhecimento da empresa.

Artigo recebido em 05.05.2004. Aprovado em 19.01.2005. 


\section{Referencias Bibliográficas}

Decreto n. 3179 (1999, 21 de setembro). Dispõe sobre a especificação das sanções aplicáveis as condutas e atividades lesivas ao meio ambiente. Brasília, DF: Presidência da República. Recuperado em 29 dezembro, 2005, de http//www.planalto.gov.br

Gazeta do Povo (2001, janeiro $\left.1^{\circ}\right)$.

Ministério Público pede indenização de $R \$ 2,3$ bilhões à Petrobrás. In: Ambicenter - Portal de Informações e Legislação Ambiental. Recuperado em 29 outubro, 2002, de www.a mbicenter.com.br/ n01011906.htm.

Conselho Nacional do Meio Ambiente (1986, janeiro 23).

Resolução 001 - Dispõe sobre critérios básicos e diretrizes gerais para o Relatório de Impacto Ambiental - RIMA. Recuperado em 22 novembro, 2004, de http:// www.mma.gov.br/conama/res/res86/ res0186.html

Conselho Nacional do Meio Ambiente (1997, dezembro 19).

Resolução 237 - Regulamenta os aspectos de licenciamento ambiental estabelecidos na Política Nacional do Meio Ambiente. em 22 novembro, 2004, de http://www.mma.gov.br/port/ conama/res/res97/res23797.html

Folha de São Paulo (2002, abril 10). Ação contra Petrobrás pleiteia maio valor da história por dano ambiental. Recuperado em 23 julho, 2004, de www1.uol.com.Br/folha/cotidiano/ ult95u49148.shl:
Jucovsky, V. L. R. S. (2002).

Responsabilidade das Empresas por Passivos Ambientais. In A. H. Benjamin (Ed.). 10 anos da ECO-92: O Direito e o Desenvolvimento Sustentável (pp. 265-282.). São Paulo: IMESP.

Lei $\mathrm{n}^{\circ} 6.938$, de 31 de agosto de 1981. (1981, setembro 2).

Dispõe sobre a Política Nacional do Meio Ambiente, seus fins e mecanismos de formulação e aplicação, e dá outras providências. Brasília, DF: Presidência da República. Recuperado em 22 novembro, 2004, de https://www.planalto.gov.br/ ccivil_03/Leis/L6938org.htm

Machado, P. A. L. (1999).

As 17 leis ambientais mais importantes. Recuperado em 20 julho, 2004, de http:// www.jornaldomeioambiente.com.br/ LegislacaoAmbiental/17leis.asp

Petrobrás Brasileiro S.A (1999).

Relatório Anual de Atividades. Rio de Janeiro, RJ: Autor.

Petrobrás Brasileiro S.A (2000).

Relatório Anual de Atividades. Rio de Janeiro, RJ: Autor.

Petrobrás Brasileiro S.A (2001).

Relatório Anual de Atividades. Rio de Janeiro, RJ: Autor. 
Ribeiro, M. S. de (1992).

Contabilidade e Meio Ambiente. Dissertação de Mestrado, Faculdade de Economia, Administração e Contabilidade da Universidade de São Paulo - FEA/USP, São Paulo, SP.

Ribeiro, M. S. de (1999).

Balanço Ambienta. (Documento de Discussão Interna 02/99). São Paulo, SP: Fundação Instituto de Pesquisas Econômicas - FIPE.

Ribeiro, M. S. de, \&

Lisboa, L. P. (1999, janeiro/fevereiro). Balanço Social. Revista Brasileira de Contabilidade, (115), pp. 74-81.
Ribeiro, M. S. de, \&

Lisboa, L. P. (2000).

Passivo Ambiental. Anais do Congresso Brasileiro de

Contabilidade, Goiânia, GO, 16. Recuperado em 23 julho, 2004, de www.eac.usp.br/eac/publicações

Santos, A. O. de,

Silva, F. B. da,

Souza, S. de, \&

Souza, M. F. R. de. (2001, setembro/ dezembro).

Contabilidade ambiental: um estudo sobre sua aplicabilidade em empresas brasileiras. Revista da Contabilidade \& Finanças, 16(27), 91. 